\title{
Spatiotemporal Changes in Mulberry-Dyke-Fish Ponds in the Guangdong-Hong Kong-Macao Greater Bay Area over the Past 40 Years
}

\author{
Wenxin Zhang ${ }^{1}$, Zihao Cheng ${ }^{1}$, Junliang Qiu ${ }^{2} \oplus$, Edward Park ${ }^{3,4,5}{ }^{\circ}$, Lishan Ran ${ }^{6} \oplus$, Xuetong Xie ${ }^{1}$ \\ and Xiankun Yang $1,7, * \mathbb{D}$
}

Citation: Zhang, W.; Cheng, Z.; Qiu, J.; Park, E.; Ran, L.; Xie, X.; Yang, X. Spatiotemporal Changes in

Mulberry-Dyke-Fish Ponds in the Guangdong-Hong Kong-Macao Greater Bay Area over the Past 40 Years. Water 2021, 13, 2953.

https://doi.org/10.3390/w13212953

Academic Editor: Athanasios Loukas

Received: 16 August 2021

Accepted: 17 October 2021

Published: 20 October 2021

Publisher's Note: MDPI stays neutral with regard to jurisdictional claims in published maps and institutional affiliations.

Copyright: (c) 2021 by the authors. Licensee MDPI, Basel, Switzerland. This article is an open access article distributed under the terms and conditions of the Creative Commons Attribution (CC BY) license (https:/ / creativecommons.org/licenses/by/ $4.0 /)$.
1 School of Geography and Remote Sensing, Guangzhou University, Guangzhou 510006, China; wenxinzhang@e.gzhu.edu.cn (W.Z.); 2980264379@e.gzhu.edu.cn (Z.C.); xiexuetong@gzhu.edu.cn (X.X.)

2 Department of Land, Environment, Agriculture and Forestry, University of Padova, Agripolis, viale dell’Università 16, 35020 Legnaro (PD), Italy; junliang.qiu@studenti.unipd.it

3 National Institute of Education, Nanyang Technological University, Singapore 637616, Singapore; edward.park@nie.edu.sg

4 Asian School of the Environment, Nanyang Technological University, Singapore 639798, Singapore

5 Earth Observatory of Singapore, Nanyang Technological University, Singapore 639798, Singapore

6 Department of Geography, The University of Hong Kong, Hong Kong, China; lsran@hku.hk

7 Rural Non-Point Source Pollution Comprehensive Management Technology Center of Guangdong Province, Guangzhou University, Guangzhou 510006, China

* Correspondence: yangxk@gzhu.edu.cn

Abstract: Mulberry-dyke-fish pond ecosystems are a representative traditional eco-agriculture in the Guangdong-Hong Kong-Macao Greater Bay Area (GBA). Investigations about the changes in the systems and their relevant water environments under the background of rapid urbanization can provide valuable information to formulate sustainable protection and development strategies. Using the Landsat images obtained after 1986, this study combined supervised classification and visual interpretation approaches, as well as water intensity index and synthesized index to identify the spatial patterns of changes in the ponds in the GBA over the past 40 years. The results indicated that during the period 1986-2013, the total surface area of the ponds in the GBA increased significantly and peaked in 2013 with a total increase of $84.63 \%$; After that, the total surface area showed a downward trend with a total decrease of approximately $31.34 \%$. The year of 2013 was identified as the milestone of the changes. The results proved that human activities have continuously influenced the spatial distribution and size of fish ponds in the past 40 years. The fish ponds had transformed from near-natural ponds with different sizes and a near-natural random distribution in the early stage into an artificial distribution and an artificial shape. Land use changes, industrial transfer, Government guidance and financial motives were the major drivers to the changes. If no effective measures are taken, this shrinking trend in the ponds will remain in the future.

Keywords: mulberry-dyke-fish pond ecosystem; spatial evolution analysis; remote sensing; Guangdong-Hong Kong-Macao Greater Bay Area

\section{Introduction}

The mulberry-dyke-fish pond ecosystem, developed by ancient Chinese farmers 2500 years ago with complex irrigation and drainage design, is an artificial eco-agriculture system which are mostly found in the Yangtze River Delta and Pearl River Delta (PRD). Conducive to the cultivation of mulberry-dyke trees, silk rearing, fish and poultry farming, the ecosystem plays an important role in energy circulation and the ecological environment protection [1]. Compared to other agricultural systems, this system has better economic and ecological performance, with advantages in regulation of droughts and floods, stable high outputs, and easy operation [2]. Currently, this traditional agriculture system is believed 
under a crisis of extinction caused by the outflow of rural population and the fast expansion of cities and towns, especially in the GBA, which now is one of the most prosperous regions in China. One of the manifestations is that, as part of the GBA, the Pearl River Delta (PRD) region is one of China's most important urban agglomerations with the fastest urbanization rate. Profited from the implementation of China's reform and opening-up policy since 1978, the area of built-up land in the PRD reached $434,570 \mathrm{hm}^{2}$ from 1988 to 1998 alone and enlarged by 1.5 times in a ten-year period. This process undoubtedly occupied ponds [1], making them more fragile because of the associated polluted water [3,4]. Moreover, views about the shrinking in the ponds could be summarized into two aspects. First are policy changes. The current average annual growth rate of national agricultural production needs to be maintained at $4.6 \%$ to meet the food needs of $22 \%$ of the global population, while the output by the ponds is not comparable with large-scale modern agriculture. The traditional pond ecosystem is thus being abandoned by farmers. Second is rural nonpoint and mini-point source pollution. Pollutants from widely used synthetic fertilizers cause various effects to the pond ecosystem, exacerbating material and energy flows within the ecosystem, thus weakening its ecosystem service. Compared with other large waterbodies, ponds are less capable of pollutant dilution, leading them to be abandoned. Under these circumstances, there have been increasing awareness to implement conservation policies for the pond ecosystem preservation. Measures such as numerical assessments, pond inventory mapping and pond ecosystem monitoring through IoT-based devices have been applied [5].

Previous studies on the ponds in the GBA mainly focused on its ecological functions, such as applications of energy theories to make synthetical and quantitative analyses based on energy structure and indices [1]. Their historical development, agricultural heritage and landscape patterns were also investigated. The pond ecosystem, as an important part of the agricultural heritage systems, has prominent agricultural heritage values for enriching production diversity and biological diversity in the GBA [6]. It is often recognized as a reflection of the harmonious coexistence of man and nature, demonstrating circular economy and ecological civilization ideas in China [7]. However, the current unclear status about the ponds has restricted these investigations.

For the monitoring of temporal and spatial changes in fish ponds, a combination of Landsat images from 2000, 2005, and 2015 has been employed to analyze them in the Foshan City in western GBA, accompanied by a similar study in Foshan, to analyze the spatial pattern changes in 1988, 1998, and 2006 [8,9]. Located in the central part of GBA, Zhongshan City has also been studied about the dynamics of its fish ponds using Landsat images in 1990, 2000 and 2013 [10]. Regarding the whole GBA, Keyhole images from 1964 and 1976 were combined with Landsat images from 1988, 2000 and 2012 to detect its ponds' spatial changes $[10,11]$. The dynamics in fish ponds have been almost released in this study, yet the time-series was still relatively short in comparison with such a long-term (more than 50 years) urbanization process in the GBA. As a result, previous studies did not fully reflect the spatiotemporal changes at a relatively complete scale. The long-term spatial dynamics found in the fish ponds is still unclear.

To respond to the research gap, based on the Landsat images obtained in the period 1986-2019, this study conducted the investigated the long-term spatiotemporal changes in fish ponds and their landscape dynamics to reveal fish ponds' historical development in the GBA. The study results will be valuable for a more comprehensive understanding of the water ecosystem dynamic development in the GBA in past decades. In addition, influencing factors were analyzed to provide an accurate reference for decision making on pond ecosystem restoration and conservation.

\section{Data and Methods}

\subsection{Study Area}

The Guangdong-Hong Kong-Macao Greater Bay Area (GBA) is located in southcentral China, composed of the "9+2 urban agglomeration" which is composed of two 
special administrative regions of Hong Kong and Macau and 9 cities from central Guangdong Province (namely, Guangzhou, Shenzhen, Zhuhai, Foshan, Huizhou, Dongguan, Zhongshan, Jiangmen and Zhaoqing). It ranges between $24.4^{\circ} \sim 21.5^{\circ} \mathrm{N}, 111.4^{\circ} \sim 115.4^{\circ} \mathrm{E}$, with a total area of about $56,000 \mathrm{~km}^{2}$ (Figure 1). The population of GBA reached approximately 70 million in 2017, with USD 1.51 trillion GDP and urbanization rate of $85.20 \%$ excluding Hong Kong and Macau. In some of the cities such as Shenzhen and Foshan, the urbanization even exceeded 90\% [12]. The GBA is currently one of the strongest economic vitality regions in China. Not only that, but it is also one of the most typical areas of fish pond adoption in China. However, with the fast industrialization and urbanization in the GBA, fish ponds have been seriously degraded in past decades [13-15]. In recent years, with the further acceleration of the transition from rural population to urban population, the built-up area in the GBA has grown at an annual rate of 3.35\% from 2000 to 2015. All high-density populated areas $\left(>10\right.$ inhabitants $\left./ 900 \mathrm{~m}^{2}\right)$ are located in built-up areas, and the average population density in rural areas has also decreased at a rate of $1 \%$ per year [16]. Accompanied by this phenomenon, decreasing farmers in the GBA would be a potential threat for fish pond management. Thus, a comprehensive analysis of the long-term dynamics of fish ponds and the impacts of urbanization on their changes is indispensable in this context.

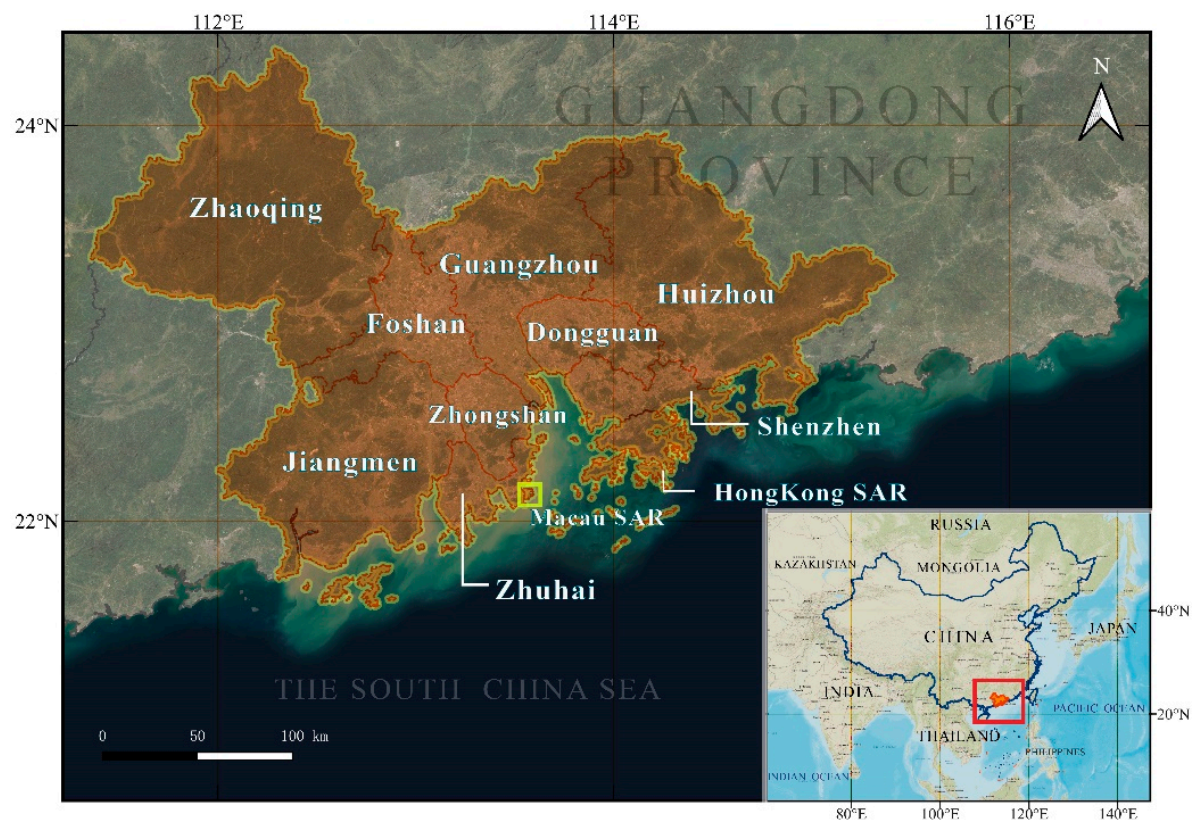

Figure 1. Administrative divisions of the Guangdong-Hong Kong-Macao Greater Bay Area (GBA). The study area covered the entire GBA. Because there are only a few fish ponds in Macau SAR, they were excluded in following investigations.

\subsection{Data Collection and Image Analysis}

\subsubsection{Data Source}

In total, 120 scenes of cloud-free Landsat images in the years1986, 1988, 1991, 1994, 1996, 1999, 2006, 2013, 2015 and 2019, were selected for fish pond delineation. Landsat-5 TM imagery were adopted from the 1980s to the 2000s, and Landsat- 8 OLI imagery were used for the 2010s. Both of the two datasets have the characteristics of multiple bands and high spectral resolution, equipped with rich information and possessed $30 \mathrm{~m}$ spatial resolution [17]. The near-infrared band is extremely sensitive to vegetation and water bodies. Preprocessing processes include radiation correction, geometric correction, mosaic and extraction by GBA boundary were performed by the Landsat images preprocessing module provided by ENVI 5.3. 
Because different regions have different degrees of urbanization. Dividing the entire study area of GBA into different sub-regions can enable a better understanding of the degrees of urbanization and their impact on pond variations in different regions. Therefore, to facilitate further analysis, the 9 prefectural cities and Hongkong Special Administrative Region (since the fish ponds in the Macau Special Administrative Region has disappeared for years, it was noted included in the study) were further divided into 25 research units (Figure 2). They included 5 units in the prefectural city of Foshan, namely, (1) Sanshui, (2) Nanhai, (3) Shunde, (4) Gaoming, and (5) Chancheng districts. Besides, 4 units are located in the city of Guangzhou, namely, (6) Panyu, (7) Baiyun and Huadu districts (combined as Unit A), (8) Nansha, (9) Yuexiu, Liwan, Haizhu, Tianhe, Huangpu, Zengcheng and Conghua districts (Combined as Unit B). The other 5 individual prefectural cities (i.e., Dongguan (10), Huizhou (11), Shenzhen (12), Zhuhai (13), Zhongshan (14)) and Hong Kong SAR (15) were set as another 6 units. Then, 4 units in the prefectural city of Zhaoqing: (16) Gaoyao district, (17) Sihui County, (18) Duanzhou district and Dinghu district (combined as Unit C), (19) Deqing County, Huaiji County, Fengkai County, Guangning County (combined as Unit D). Further, there are 6 units in the prefectural city of Jiangmen: (20) Heshan city, (21) Xinhui district, (22) Taishan city, (23) Jianghai district, (24) Pengjiang district, (25) Kaiping city and Enping city (combined as Unit E).

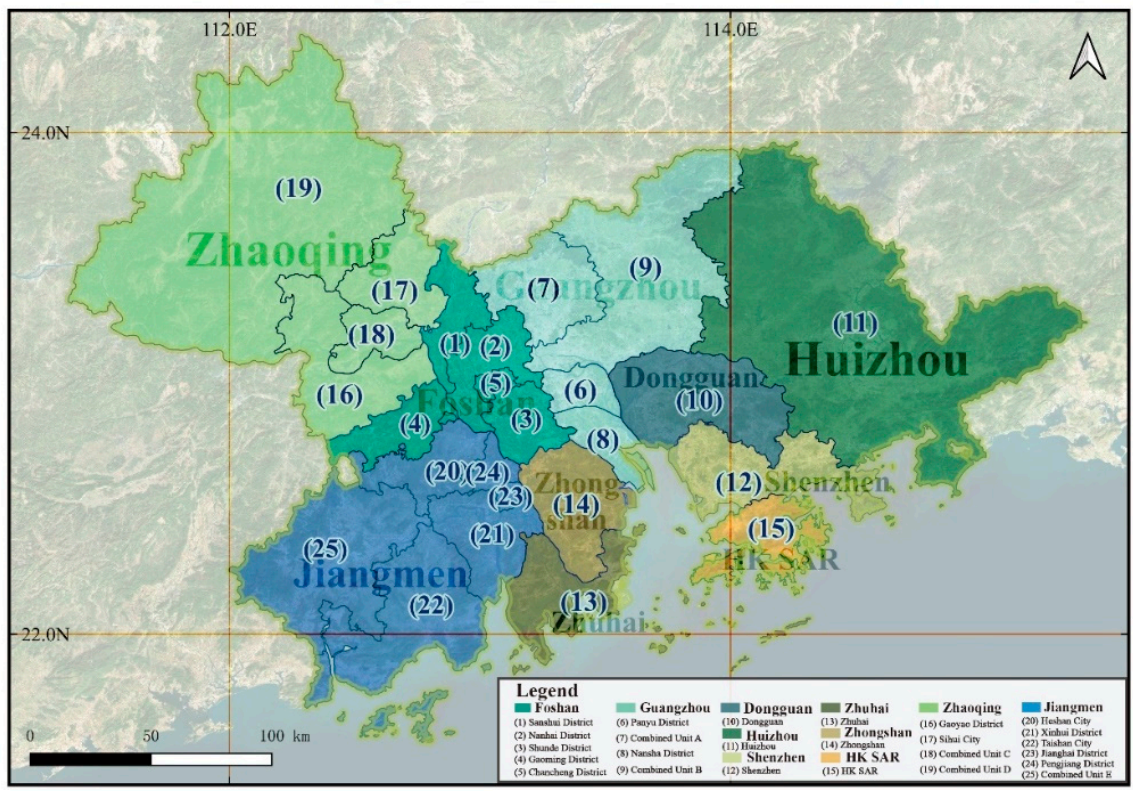

Figure 2. The location of 25 research units divided.

To ensure image classification accuracy, field investigations to collect fish ponds' spectral information using portable ASD FieldSpec were conducted in cities such as Foshan and Guangzhou where fish ponds are commonly located (Figure 3). The field-collected spectrum curves of fish ponds were added as part of the spectral library for classification. The accuracy assessment was proposed by building the confusion matrix comparing the extraction results and the accuracy assessment samples we designed based on Landsat images, combined with Google Earth historical images, field survey data and historical land use data, etc. Then, the Kappa coefficient calculated form confusion matrix was adopted to examine the accuracy of the classification results (Figure 4). 

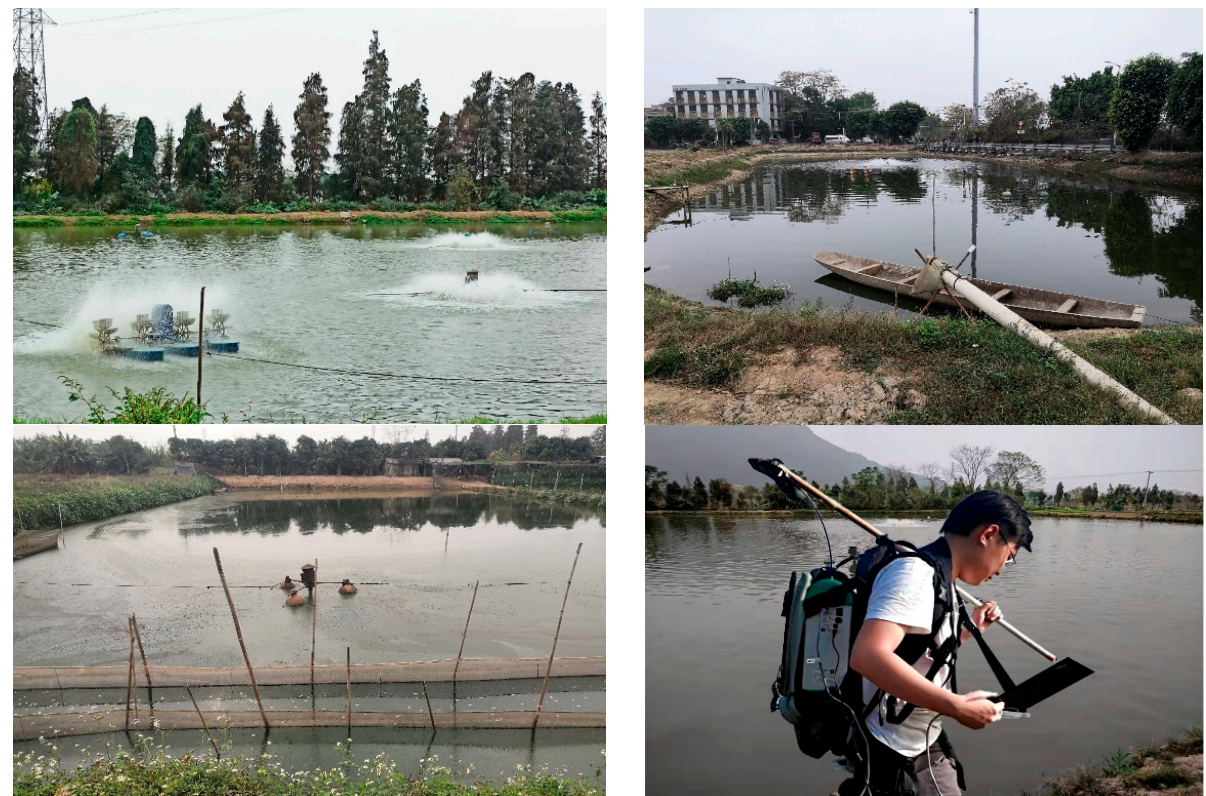

Figure 3. Photos of field investigations for the collection of ponds' spectral information. The photos were taken by the authors.

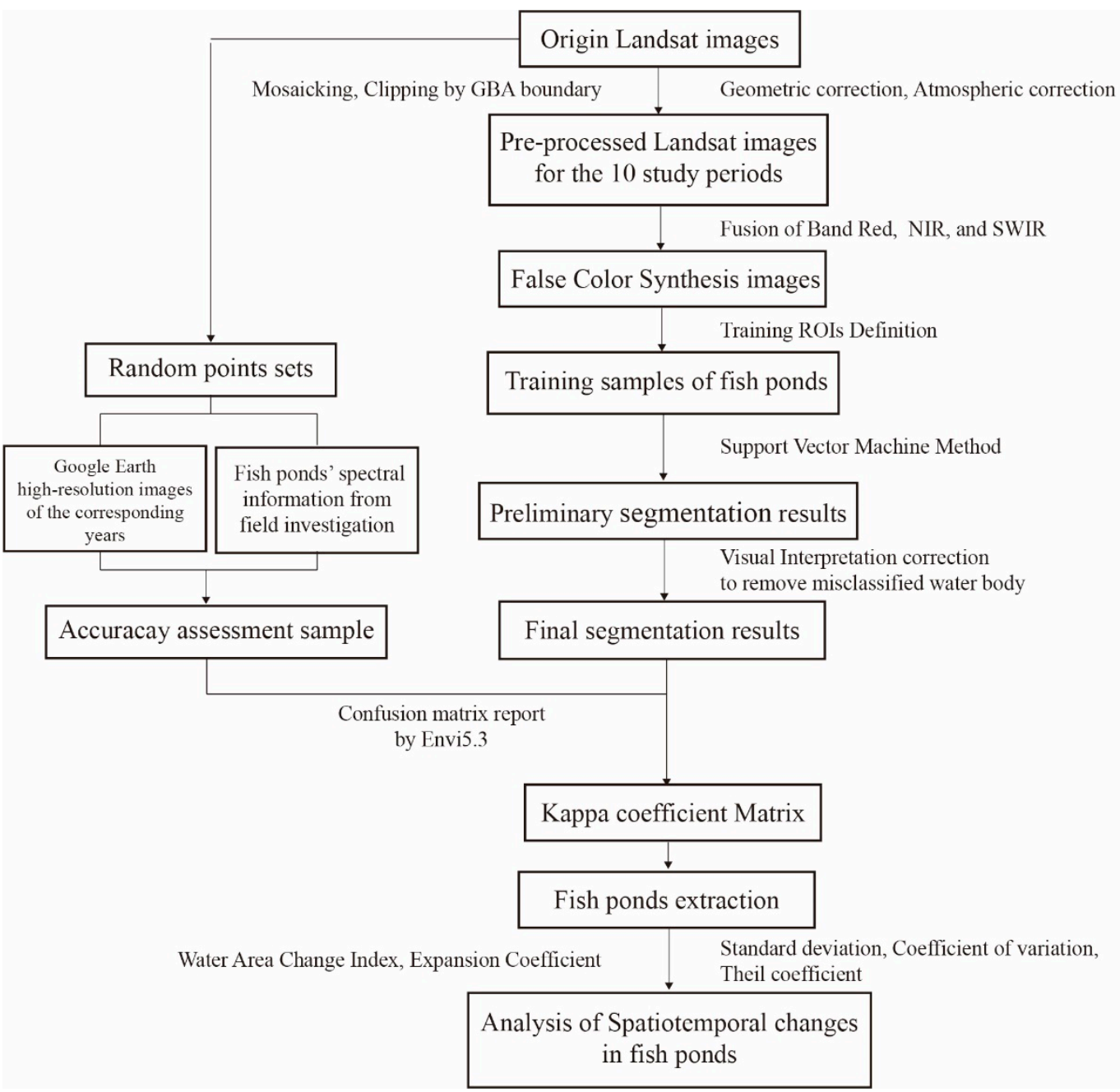

Figure 4. Flowchart for image classification and analysis. 


\subsubsection{Image Classification}

After the pre-processing of the images, the standard images in the study periods were obtained (Figure 5) to perform classification by the support vector machine algorithm. Figure 6 showed the representative patterns of waterbodies in Landsat images. The areas in blue or black colors with a clear rectangular or square boundary are fish ponds, while the rivers that extends in strip shapes.

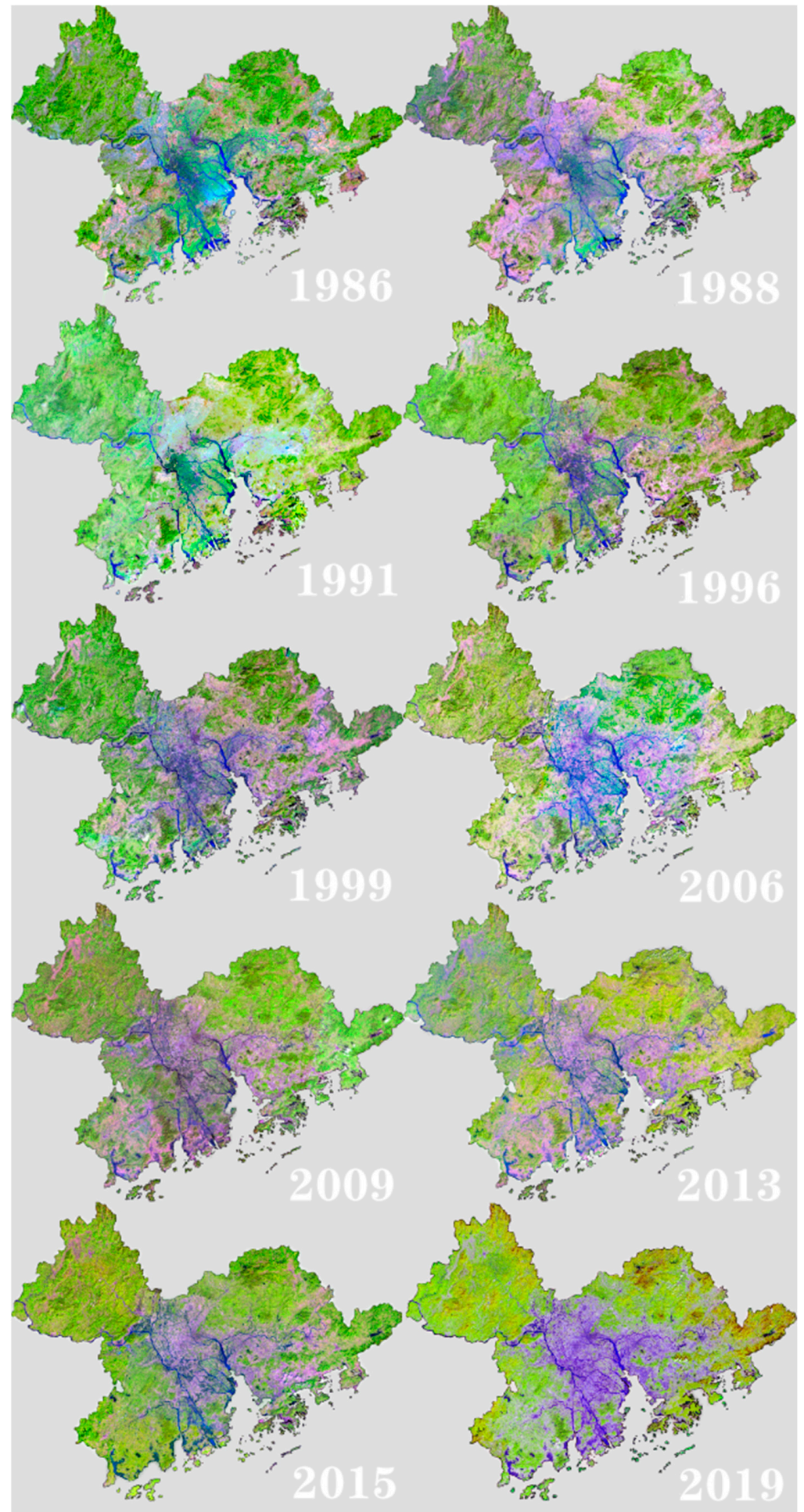

Figure 5. Pre-processed Landsat images for the 10 study periods. 


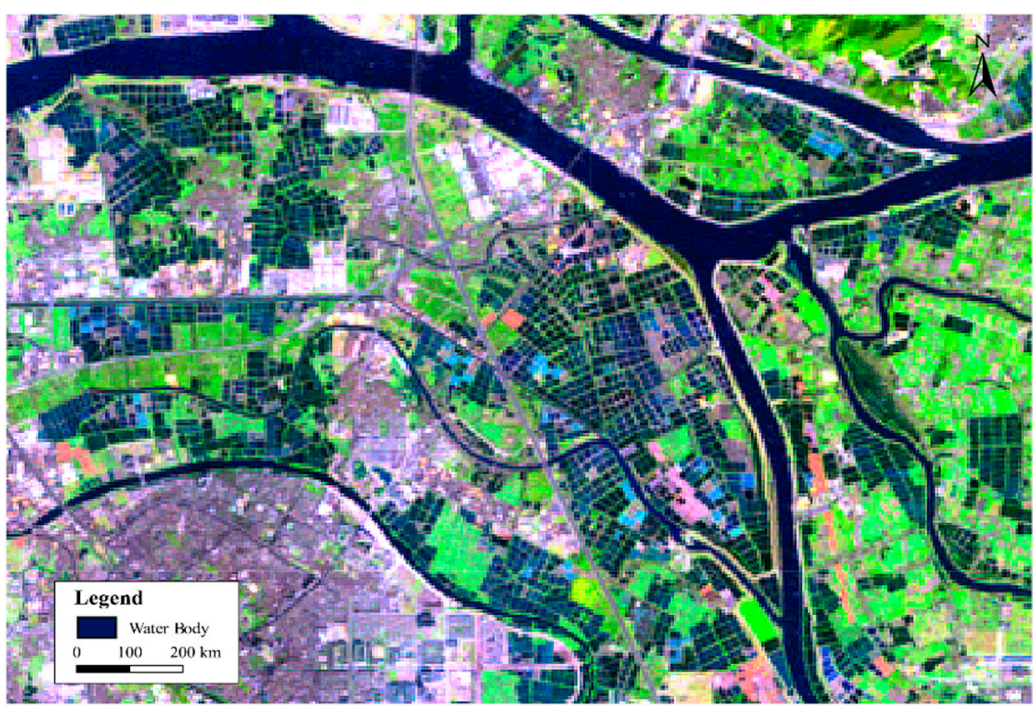

Figure 6. Representative morphological features of fish ponds in Landsat images.

Some initial information can be obtained from these pre-processed images (Figure 5). Regarding image quality, it can be seen that the image quality of the early Landsat satellite images is somewhat lower than the recently acquired Landsat OLI images. It can be clearly seen that the early satellite images were fuzzier than the latest ones, indicating more noises in these images. In addition, it was observed that the urbanization in the GBA has experienced rapid development. The built-up area (in purple color) has substantially expanded.

\subsection{Methods}

\subsubsection{Quantitative Evaluation Method}

The standard deviation $(S D)$ is the square of the deviation between the standard value of the fish pond size and the average area in each period. It was used to reflect the dispersion of the ponds within each period. Therefore, a larger $S D$ indicates a greater difference in pond size. The coefficient of variation $(C V)$ is the ratio of the standard deviation $(S D)$ of the pond area to the corresponding average in each period. A larger $V$ suggests a higher relative difference in pond size within each study unit [18].

The Theil coefficient $(T)$ indicates the regional inequality and is used to quantify the degree of difference in individual pond sizes. A larger $T$ indicates a larger inequality in pond size. In the formula, $x_{i}$ is the individual pond area; $x_{0}$ is the mean value of the pond area. $N$ is the total number of ponds.

$$
\begin{gathered}
S D=\sqrt{\frac{1}{N} \sum_{i=1}^{N}\left(x_{i}-x_{0}\right)} \\
C V=\frac{S D}{x_{0}} \\
T=\frac{1}{N} \sum_{i=1}^{N} \ln \frac{x_{0}}{x_{i}}
\end{gathered}
$$

\subsubsection{Water Area Change Index $(W)$}

The water area change intensity index indicates the rate of the areal change of the ponds in a specific period.

$$
W=100 \% \times \frac{S_{b}-S_{a}}{S_{a} \times \Delta t},
$$


where, $S_{a}$ and $S_{b}$ represent the area of the ponds in the previous period a and the current period $\mathrm{b}$, respectively, $\Delta t$ represents the timespan between periods a and $\mathrm{b}$.

\subsubsection{Expansion Coefficient $(E)$}

Expansion Coefficient is an important quantitative indicator to measure the development and change in fish ponds:

$$
E=\prod_{i=1}^{3} e_{i}
$$

where, $E$ represents the expansion coefficient, which is obtained by multiplying the internal structure transition coefficient $\left(e_{1}\right)$, the spatial structure transition coefficient $\left(e_{2}\right)$ and the expansion coefficient $\left(e_{3}\right)$.

Internal structure transition coefficient: $e_{1}=\left|P_{t}-P_{t-1}\right|, e_{1}$ in the formula represents the relative areal change of ponds. $P_{t}$ represents the areal percentage of ponds in the total area in current period, and $P_{t-1}$ represents the one in the previous period.

Spatial structure transition coefficient: $e_{2}=\left|S_{t}-S_{t-1}\right|, S_{t}$ and $S_{t-1}$ respectively represent the total fish pond area in the last and the first periods.

Expansion coefficient: $e_{3}=\left|\sqrt[t]{S_{t} / S_{0}}-1\right| . e_{3}$ is for the gradient change rate of fish ponds; $S_{t}$, and $S_{0}$ respectively represent total pond area for the last and first periods. $T$ is the research period.

In order to discriminate the patterns of the pond changes of each study unit, the 26 study units were generally divided into 4 patterns: fast growing $(E>40)$, weak growing $(40>E>1)$, stable $(1>E>0)$, and shrinking $(E<0)[19,20]$.

\subsubsection{Kappa Coefficient}

The Kappa coefficient is an index used for consistency testing proposed by Cohen in 1960 [21]. For images classification, consistency is whether the predicted results of the model are consistent with the actual classification results.

$$
\text { Kappa }=\frac{P_{o}-P_{c}}{1-P_{c}},
$$

In the formula, $P_{0}$ is the overall accuracy of the classification, which represents the probability that the classification result is consistent with the actual feature type for each random sample; $P_{c}$ represents the probability that the classification result caused by chance is consistent with the actual feature type based on the evaluation criteria proposed by Cohen, higher than 0.8 can be regarded as the consistency of the best gradient. In this study, the calculation of the Kappa coefficient is based on the confusion matrix report from Envi 5.3.

\section{Results}

\subsection{The Dynamics of Fish Ponds across the GBA}

Figure 7 shows the overview of pond dynamics over the 10 periods in GBA. Based on the water area change index $(W)$ in Figure 8 , it can be seen that the total pond area firstly showed an incipiently increasing trend, followed by a decreasing trend. The fluctuation of $\mathrm{W}$ is basically consistent with the evolution of fish ponds in the GBA. From 1986 to 1994, fish ponds demonstrated a continuous rise from $106,603 \mathrm{hm}^{2}$ to $187,153 \mathrm{hm}^{2}$, which is an enlargement of with a total of area of $80,550 \mathrm{hm}^{2}$ or a relative increase of $75.5 \%$. Accordingly, $W$ also performed an accelerated expansion and peaked in 1994. Since then, the areal change fluctuated within a small range until 2009, which means that fish ponds were under a relatively stable status during that period. In 2009, the area fell slightly to $184,589 \mathrm{hm}^{2}$, accompanied by an increase, and reached the maximum value of $196,326 \mathrm{hm}^{2}$ in 2013. After that, there was a decreasing trend from 2013 to 2019, with an average annual shrinkage of 10,242 $\mathrm{hm}^{2}$; meanwhile, $W$ also maintained a negative growth. By 2019 , the 
area had shrunk to $134,874 \mathrm{hm}^{2}$ with an overall decrease of $31.3 \%$, but the total area was still larger than 1986.

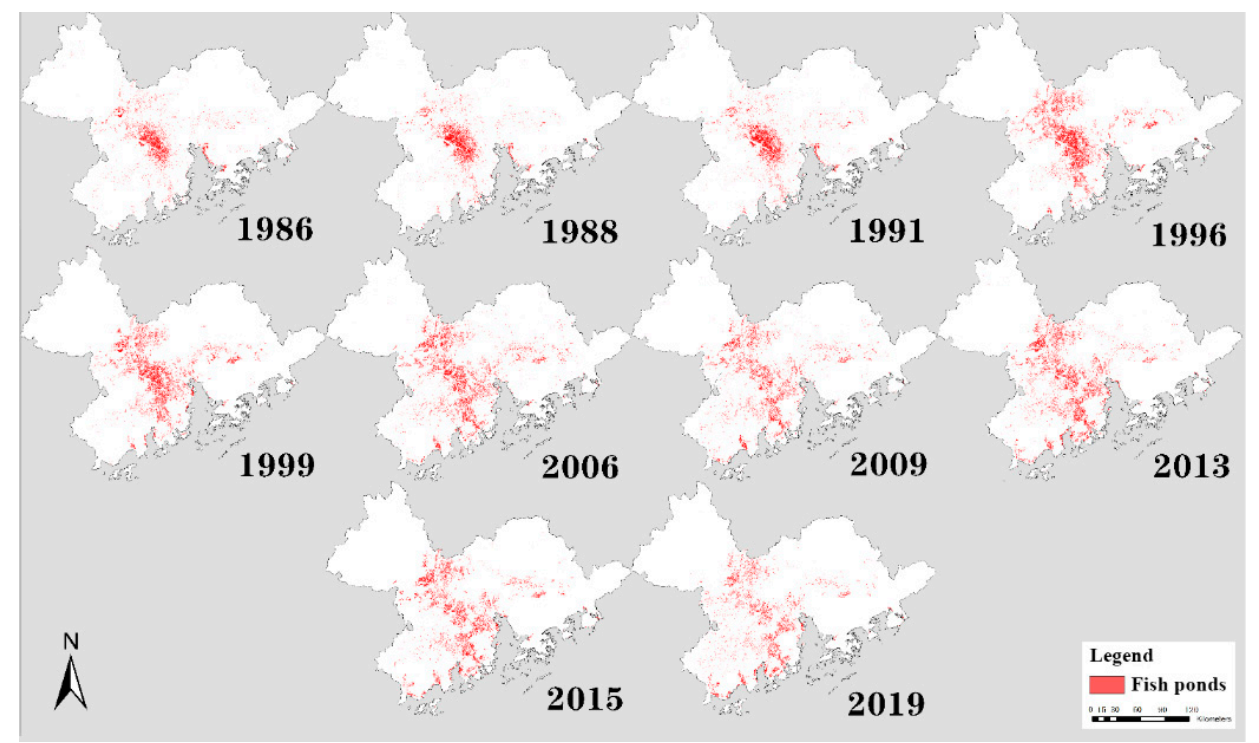

Figure 7. Spatial distribution of fish ponds in the GBA in the 10 different study periods.

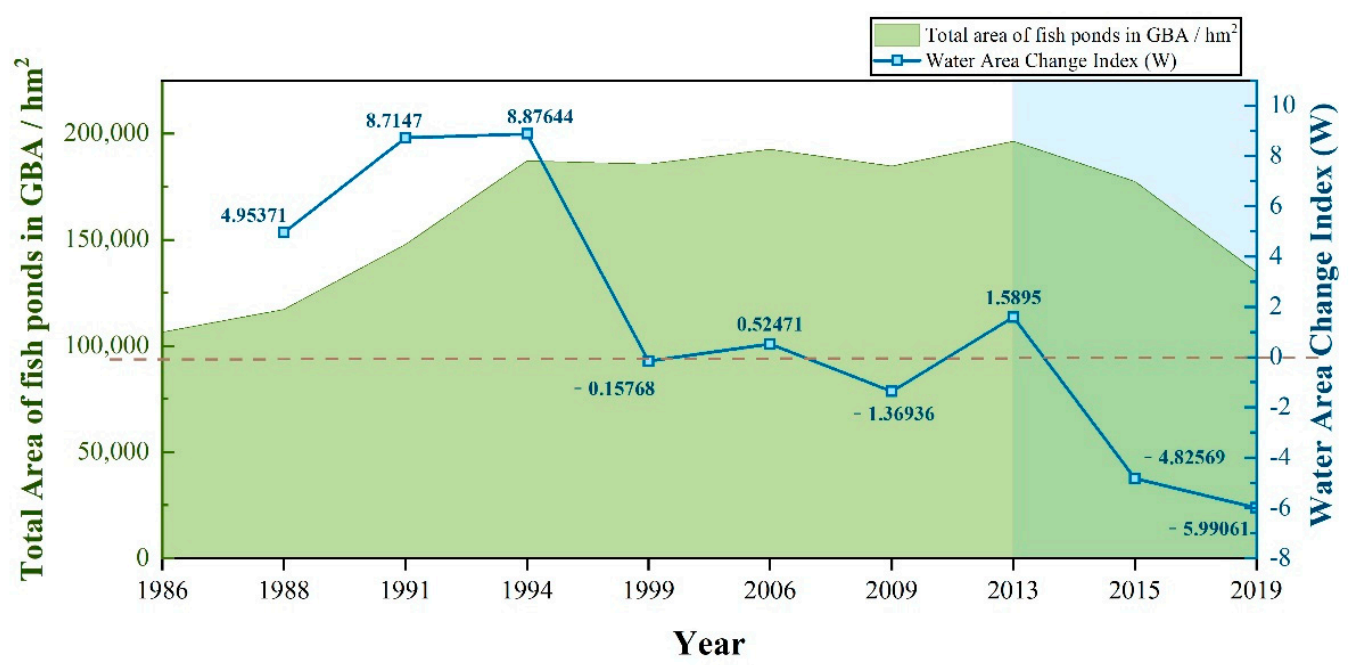

Figure 8. Water area change index and pond areal fluctuation in the GBA from 1986 to 2019.

According to the $S D$ change for each period, the spatial distribution of fish ponds in the whole GBA could be divided into three phases (1986-1994, 1994-2013 and 2013-2019 in Figure 9, and Table 1). The increasing phase between 1986 and 1994 indicated that the differences in spatial distribution of the fish ponds increased during this phase. Geographically, it could also be seen in Fig. 4 that the fish ponds were mainly located in the middle of the GBA in early period, but gradually spread to the east and south of the GBA. The $S D$ index dropped to $63,026.68$ in 2009 , showing fish ponds turned into a diffused spatial distribution. This can also be seen in Figure 7, the pond density increased, and the spatial distribution expanded outward. After they rebounded in 2013, the index kept decreasing to $52,474.643$ in 2019, illustrating that the distribution shows a trend of initial agglomeration and subsequent diffusion between 2009 and 2019. 


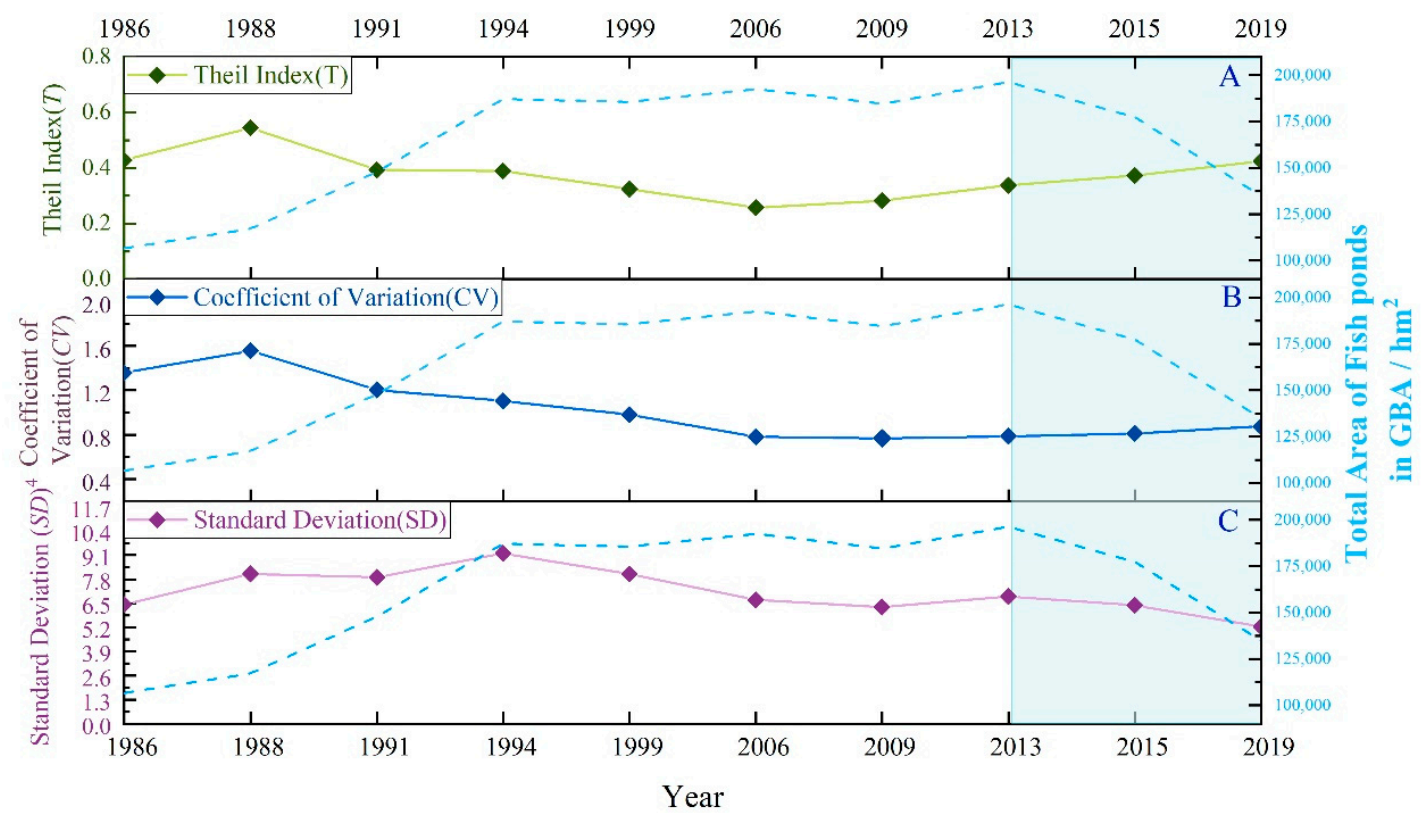

Figure 9. Fluctuation of three statistical indices compared to the areal changes of fish ponds from 1986 to 2019. (A): Theil index $(T) ;(\mathbf{B})$ : coefficient of variation $(C V)$. (C): standard deviation $(S D)$.

Table 1. Statistical results of fish ponds in GBA from 1986 to 2019.

\begin{tabular}{ccccc}
\hline Years & Area/hm $\mathbf{h}^{\mathbf{2}}$ & Standard Deviation & $\begin{array}{c}\text { Coefficient of } \\
\text { Variation }(\mathbf{C V})\end{array}$ & Theil Index (T) \\
\hline 1986 & $106,602.8$ & $64,359.503$ & 1.358 & 0.428 \\
1988 & $117,164.4$ & $80,927.218$ & 1.554 & 0.544 \\
1991 & $147,796.0$ & $78,997.455$ & 1.203 & 0.393 \\
1994 & $187,153.1$ & $91,933.360$ & 1.105 & 0.389 \\
1999 & $185,677.6$ & $80,891.375$ & 0.980 & 0.324 \\
2006 & $192,497.4$ & $66,908.650$ & 0.782 & 0.257 \\
2009 & $184,589.5$ & $63,026.680$ & 0.768 & 0.282 \\
2013 & 1963.5 .6 & $68,612.618$ & 0.786 & 0.338 \\
2015 & $177,377.5$ & $63,978.322$ & 0.812 & 0.373 \\
2019 & $134,873.6$ & $52,474.643$ & 0.875 & 0.424 \\
\hline
\end{tabular}

The coefficient of variation and Theil coefficient in each year reflected that, there were large differences in the size and area of fish ponds in the early stage, but the ponds became increasingly homogeneous in the later period. From 1986 to 2009, the coefficient of variation dropped significantly from 1.358 in 1986 to 0.768 in 2009, and the Theil coefficient dropped from 0.428 to 0.282 , indicating that the differences in pond size gradually decreased during this period. In the next stage 2009-2019, the Theil coefficient fluctuated basically in a relatively stable status. the variation coefficient also changed consistently to the Theil coefficient. The results proved that human activities have continuously influenced the distribution and size of fish ponds in the past 40 years. The fish ponds had transformed from an early near-natural ponds with different sizes and a near-natural random distribution into an artificial distribution and an artificial shape.

\subsection{The Areal Variation Trends in the Prefectural Cities}

In 1986, Foshan had the largest number of fish ponds, followed by Zhongshan and Zhaoqing. However, by 2019, Jiangmen has become the largest, followed by Foshan and Zhaoqing. Considering the area of the fish ponds and the overall areal variations at the initial and the end of the study period, the prefectural cities can be roughly divided into the following three categories: 
The growing cities (Figure 10) include Guangzhou, Huizhou, Zhuhai, Zhaoqing, Jiangmen, and Zhongshan. The trend of areal variation from 1986 to 2019 shows a fluctuating growing trend, but the peaks appeared at slightly different times. The year 2013 was the peak of Guangzhou, Zhuhai, Zhaoqing, and Jiangmen. As for Zhongshan, in addition to the peak in 1994, it also reached a second peak in 2013. All the five prefectural cities experienced a decline after 2013. Similarly, Huizhou began to decline after a slight rise in the 2013-2015 period.

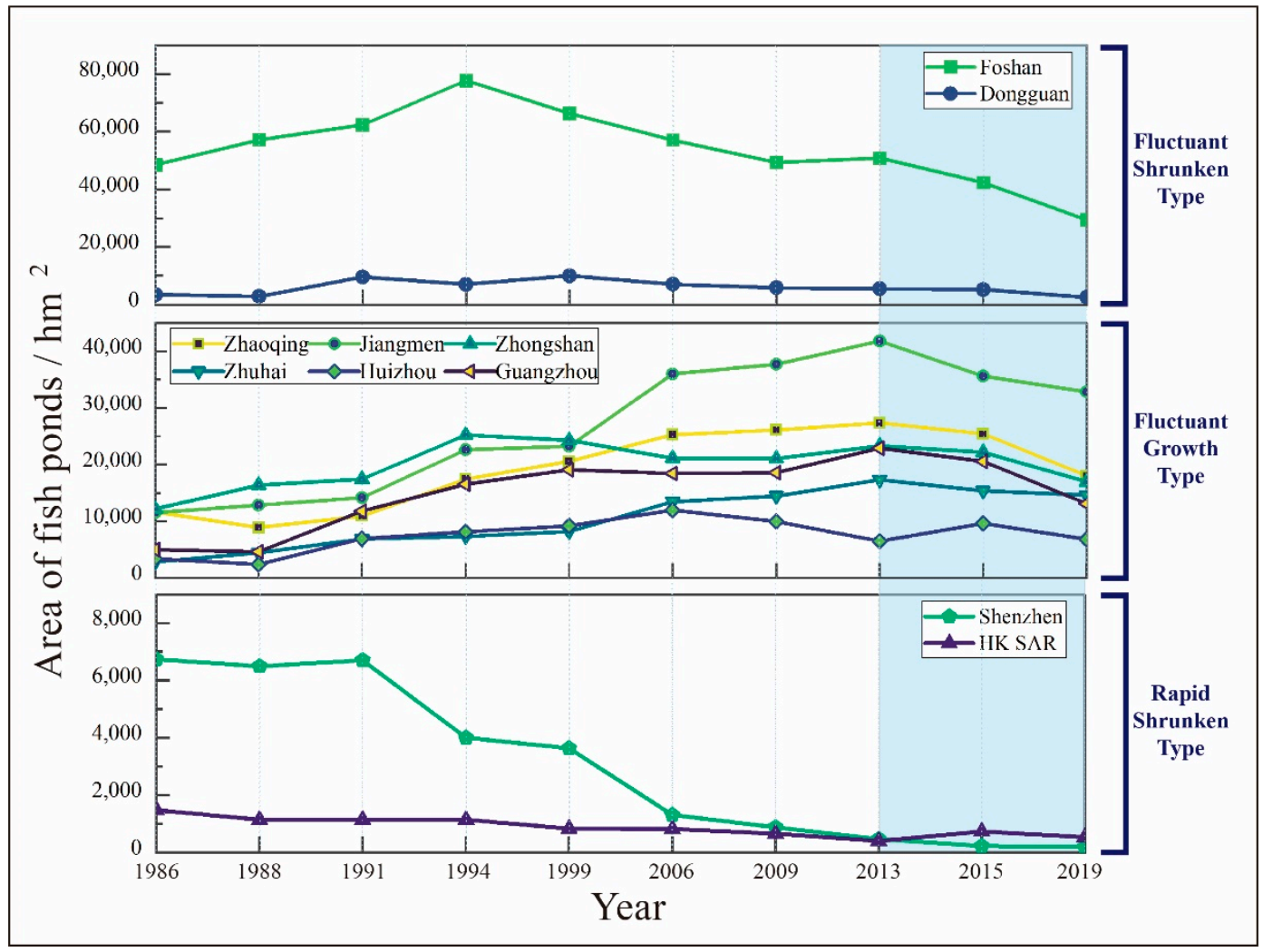

Figure 10. The trends for three representative changes in fish ponds in the GBA.

The shrinking fish ponds were observed in Foshan and Dongguan (Figure 10). In 2019 , the area of fish ponds in Foshan decreased by $39.43 \%$. In comparison, the area of fish ponds in Dongguan decreased by $27.90 \%$. In terms of the variation trends, both cities maintained a fluctuated growth first and then a gradual shrinkage. The maximum area of the fish ponds in two cities happened in the 1990s. In 1994, Foshan's fish ponds reached the maximum area of $77,729 \mathrm{hm}^{2}$; in 1999, the area of Dongguan reached the highest value of $9995 \mathrm{hm}^{2}$. The minimums in both appeared in 2019, indicating that the shrinking trends will remain.

The rapid shrinking cities (Figure 10) include Shenzhen and Hong Kong. Overall, fish ponds in both cities have almost disappeared. By 2019, the area of fish ponds in Shenzhen decreased by $97.1 \%$; the counterpart in Hong Kong also decreased by $63.8 \%$. The areas of fish ponds in the two regions still maintained a decreasing trend with slight fluctuations, with the maximum value in 1986 and the minimum value in 2019.

It should be noted that, in 2013, except for Huizhou, Shenzhen, and Hong Kong, the other eight cities all reached a peak before showing a significant drop. Research on this milestone is meaningful to understand the development of fish ponds over the past 10 years. 


\subsection{The Spatio Patterns in Areal Dynamics among Study Units}

The expansion coefficients $(E)$ were calculated for the 25 study units in the GBA in each period. The study periods were divided into two stages-the first stage (1986-2013) and the second stage (2013-2019).

\subsubsection{The First Stage (1986-2013)}

At the first stage, the types of the study units were divided as follows:

Fast growing units, included Sihui, Sanshui, Panyu, Nansha, Xinhui, Taishan, Zhuhai, mainly located in central and southern GBA. Such cities obtained an expansion coefficient larger than 89.0, expansion rate greater than 5.6\%, and internal structure transition coefficient, spatial structure transition coefficient both greater than 2.0. From 1986 to 2013, the total area of fish ponds in this units increased from $12,595 \mathrm{hm}^{2}$ to $80,369 \mathrm{hm}^{2}$, with a total of $538.10 \%$, which made the areal proportion of these units increased from $11.81 \%$ to $40.94 \%$.

Growing unites, included Gaoyao, Gaoming, Heshan, Nanhai, Zhongshan, and Combined units B, C, and E, mainly located in the western GBA. Such units received a expansion coefficient higher than 1.4, expansion rate greater than 0.8 , and internal structure transition coefficient, spatial structure transition coefficient both greater than 0.3. From 1986 to 2013, the area of ponds in these units increased from $40,033 \mathrm{hm}^{2}$ to $77,009 \mathrm{hm}^{2}$, with a total of $92.36 \%$, making the areal proportion of fish ponds in these units increased from $37.55 \%$ to $39.22 \%$.

Stable unites, included five units in total, namely, Huizhou, Dongguan, Pengjiang, Jianghai, and Combined Unit B. Such units are relatively stable without significant increase: all of the expansion coefficient values were stable between 0 and 1 , expansion rate and internal structure transition coefficient were both relatively low. During the first period, Dongguan maintained a relatively stable with slight growing, the apparent shrinkage of the area appeared in 2019, which lied in the second period, from 1986 to 2013. Although the area of fish ponds in this units increased from $12,937 \mathrm{hm}^{2}$ to $20,494 \mathrm{hm}^{2}$, a total of $58.41 \%$, the pond areal proportion of the units decreased from $12.14 \%$ to $10.44 \%$. Therefore, compared to other units, this increase was very insignificant.

Shrinking units, included Chancheng, Shunde, Shenzhen, Combined Unit D, and Hong Kong, mainly located in north-western and south-eastern GBA. These units obtained negative expansion coefficient and internal structure transition coefficient, with continued shrinking in total pond surface area. From 1986 to 2013, the total area of ponds in these units decreased from $41,038 \mathrm{hm}^{2}$ to $18,454 \mathrm{hm}^{2}$, a drop in $55.03 \%$. The total pond areal proportion of the units decreased from $38.50 \%$ to only $9.40 \%$.

\subsubsection{The Second Stage (2013-2019)}

Slight growing units, included only one unit of Taishan. From 2013 to 2019, the total area of ponds in this unit increased from $11,233 \mathrm{hm}^{2}$ to $13,430 \mathrm{hm}^{2}$, with a total of $19.5 \%$. The relative areal proportion of this unit increased from $5.72 \%$ to $9.96 \%$.

Stable unites, included Huizhou, Combined Unit E, and Hong Kong (Figure 11b). From 2013 to 2019, the total area of fish ponds in these units increased from 10,922 hm² to $11,725 \mathrm{hm}^{2}$, with a total of $7.35 \%$. The relative areal proportion of these units increased from $5.56 \%$ to $8.69 \%$.

Shrinking units, included Sanshui, Nanhai, Shunde, Gaoming, Chancheng, Panyu, Nansha, Dongguan, Shenzhen, Zhuhai, Zhongshan, Gaoyao, Sihui, Heshan, Xinhui, Jianghai, Pengjiang, Combined Units A, B, C and D, 21 units in all. It can be seen, during the stage, most of them were shrinking units. From 2013 to 2019, the area of fish ponds in these units dropped from $174,171 \mathrm{hm}^{2}$ to $109,719 \mathrm{hm}^{2}$, a total of $-37.00 \%$, making the relative areal proportion of this units decreased from $88.72 \%$ to $81.35 \%$. At the same time, the water area change index (Figure 12) also showed that the average water body change index of each unit from 2013 to 2019 was $-5.67 \%$, and the average annual change for each unit was $-4.11 \mathrm{hm}^{2}$. Among them, Shunde, Zhongshan and Sanshui, which were the top three in absolute annual shrinking in fish ponds, with an average annual shrinkage of $1164 \mathrm{hm}^{2}$, 
$1055 \mathrm{hm}^{2}$ and $969 \mathrm{hm}^{2}$, respectively. In Chancheng, Shenzhen and Heshan, where the average annual relative shrinking in fish ponds ranked the top three. The water body change index was $-11.44 \%,-9.81 \%$ and $-9.77 \%$ respectively.

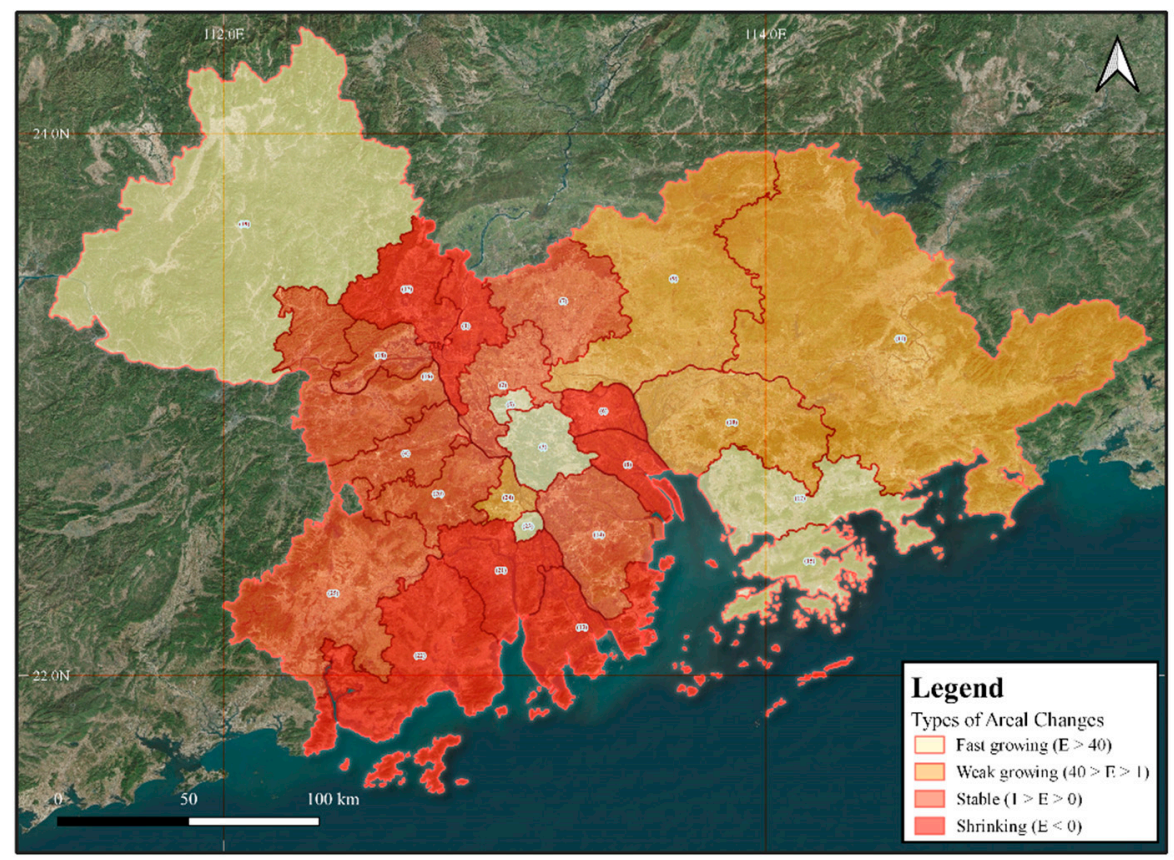

(A)

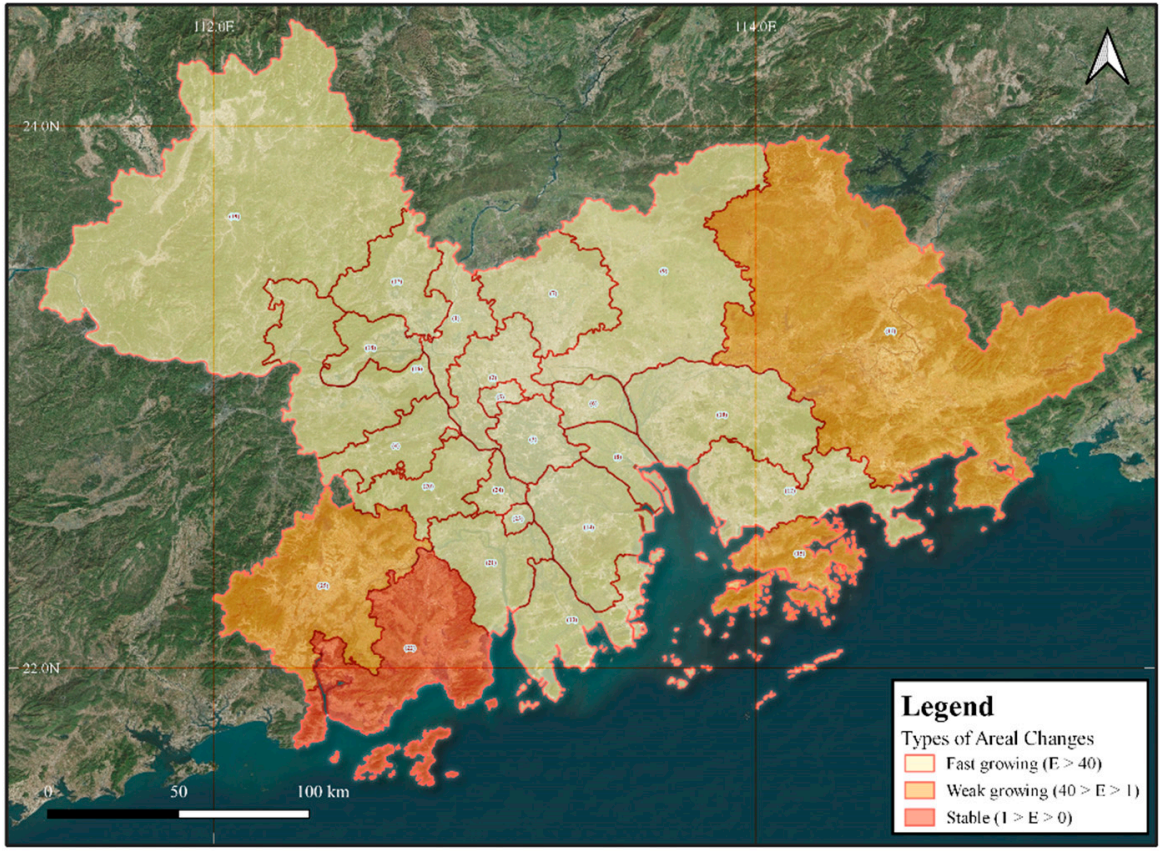

(B)

Figure 11. The spatiotemporal patterns in areal dynamics in the study units in the two different stages: (A) the first stage from 1986 to 2013; (B) the second stage from 2013 to 2019. 


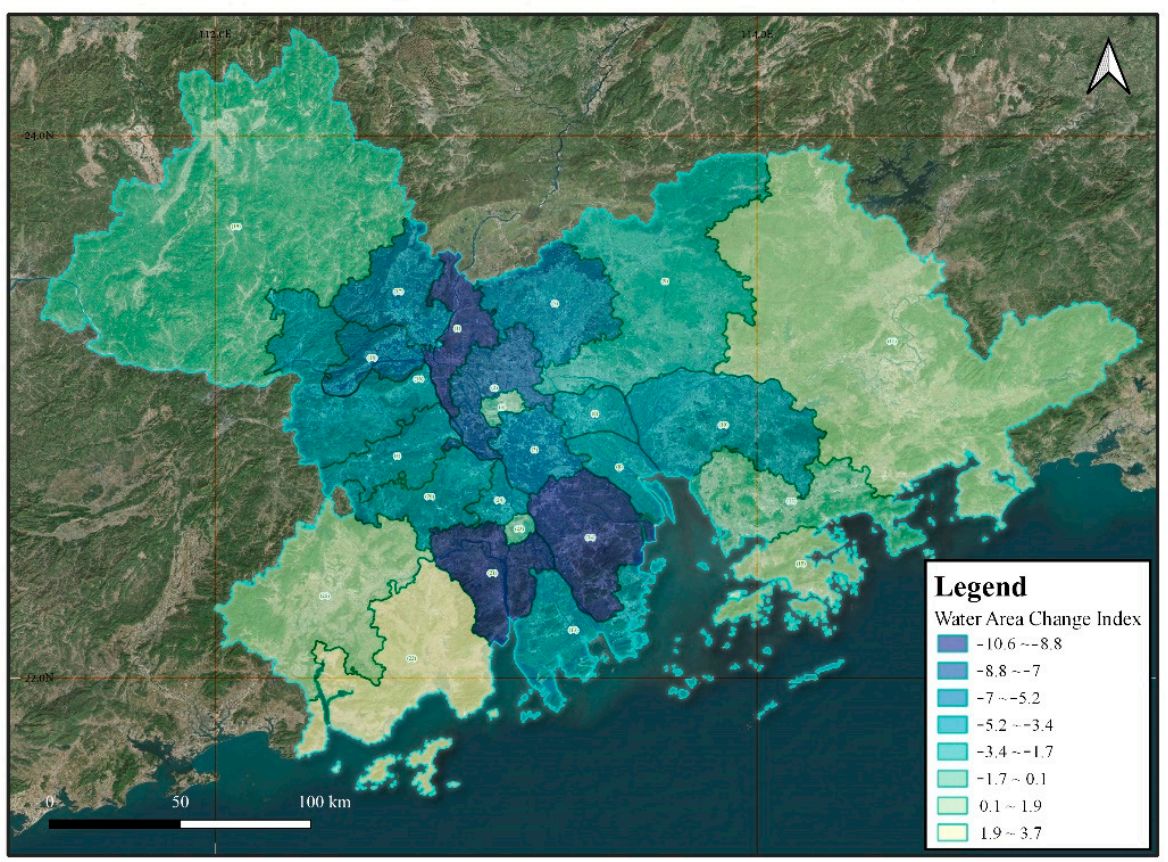

Figure 12. Distribution of each unit for waterbody area change index in GBA from 2013 to 2019.

It can be seen that taking 2013 as the milestone, the spatial dynamic patterns of fish ponds in the GBA have changed significantly. Except for the four units of Taishan, Hong Kong, Huizhou, Combined Unit B, which are classified as weakly expansionism or relatively stable, the other 21 units all experienced shrinking.

\section{Discussion}

\subsection{Uncertainty Analysis}

\subsubsection{Accuracy Assessment}

Previous studies have proved that the support vector machine (SVM) method has high interpretation accuracy in fish pond extraction [22]. This could also be seen in Figure 13A that the water body delineation using SVM was satisfactory.

Sometimes, problems happened to some narrow ponds with width less than $30 \mathrm{~m}$, which could be false to be identified in Landsat imagery due to relative coarse spatial resolution (Figure 14) [23]. However, in consideration of the satellite return interval, Landsat satellites were the best choice. Table 2 has shown that the Kappa coefficient for each yearly classification results were all above 0.8 , capable for the data analysis. To maintain the data quality, visual interpretation was combined to improve classification results; yet the result may still be affected by mixed pixels due to images' resolution (Figure 13B).

In addition, it should be noted that, because the study area is located in the subtropical area, there are almost no cloud-free satellite images available in the monsoon season. Most of the images used in this study were acquired during dry seasons. Generally, the surface area of the water bodies varies greatly during from monsoon season to the dry season, and the area during the dry season is commonly significantly smaller than in the monsoon season. However, as reported in Section 3, most of the fish ponds are now artificial, and changes in water surface area are rarely affected by season switch. Therefore, this impact can be safely ignored in this study. Besides, for a time scale of over 40 consecutive years, the Kappa coefficient of over 0.8 is well enough to perform a relatively accurate change trajectory of fish ponds in such a large scale of this study. However, it should be noted that, when similar methods are used to evaluate natural water bodies, this effect should be considered. 


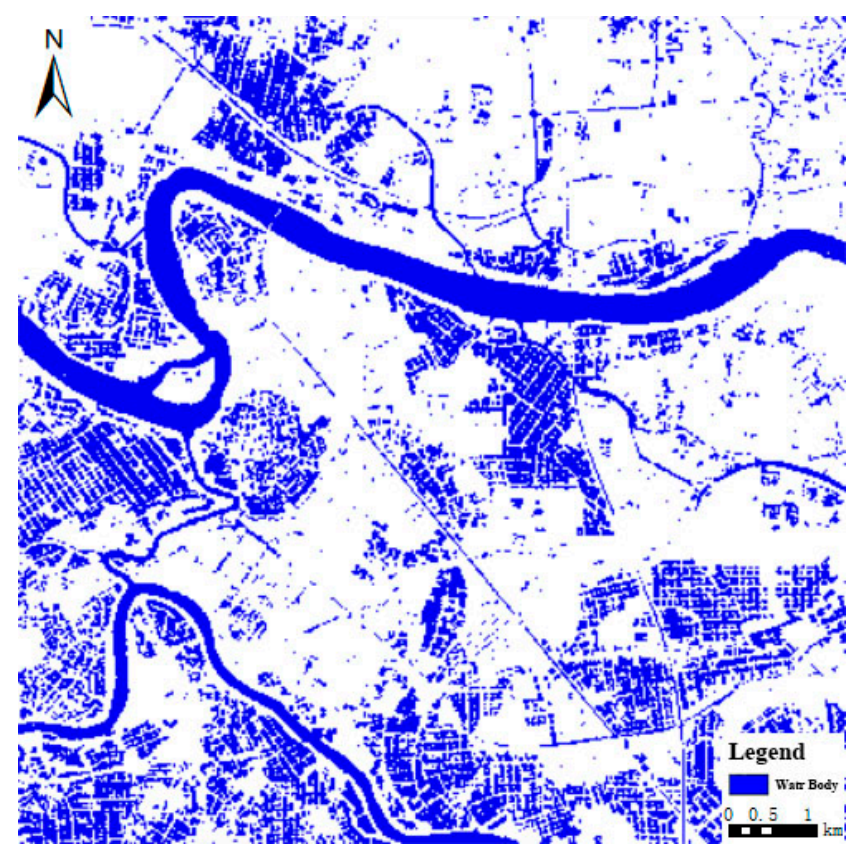

(A)

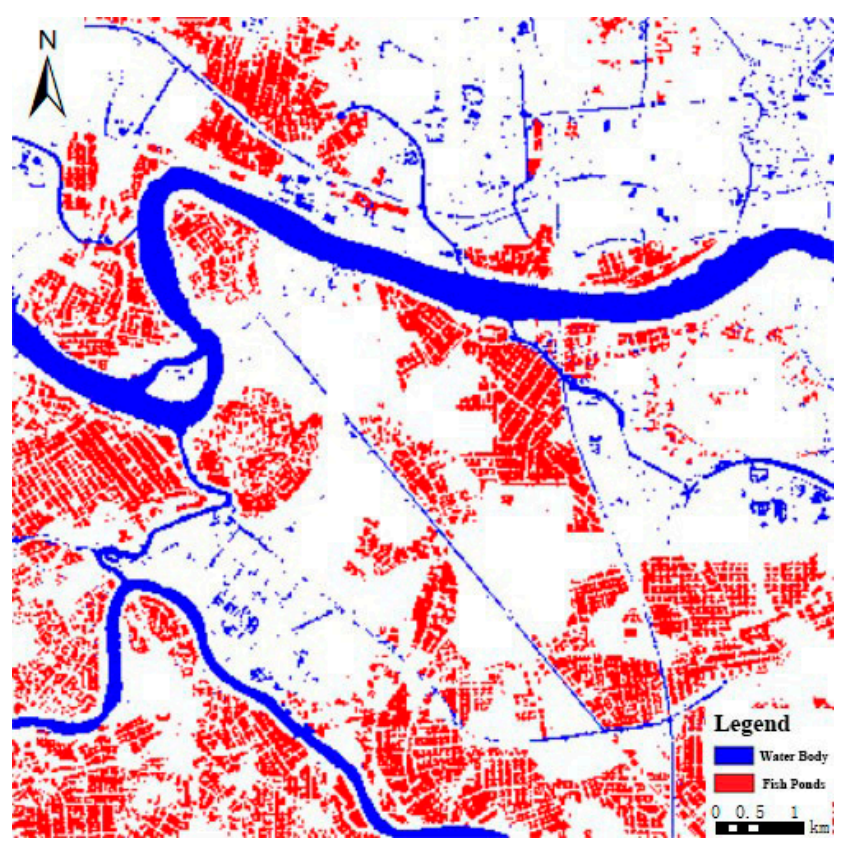

(B)

Figure 13. Image classification results and the subsequent visual interpretation results: (A) the classification results using SVM; (B) the results of visual interpretation.

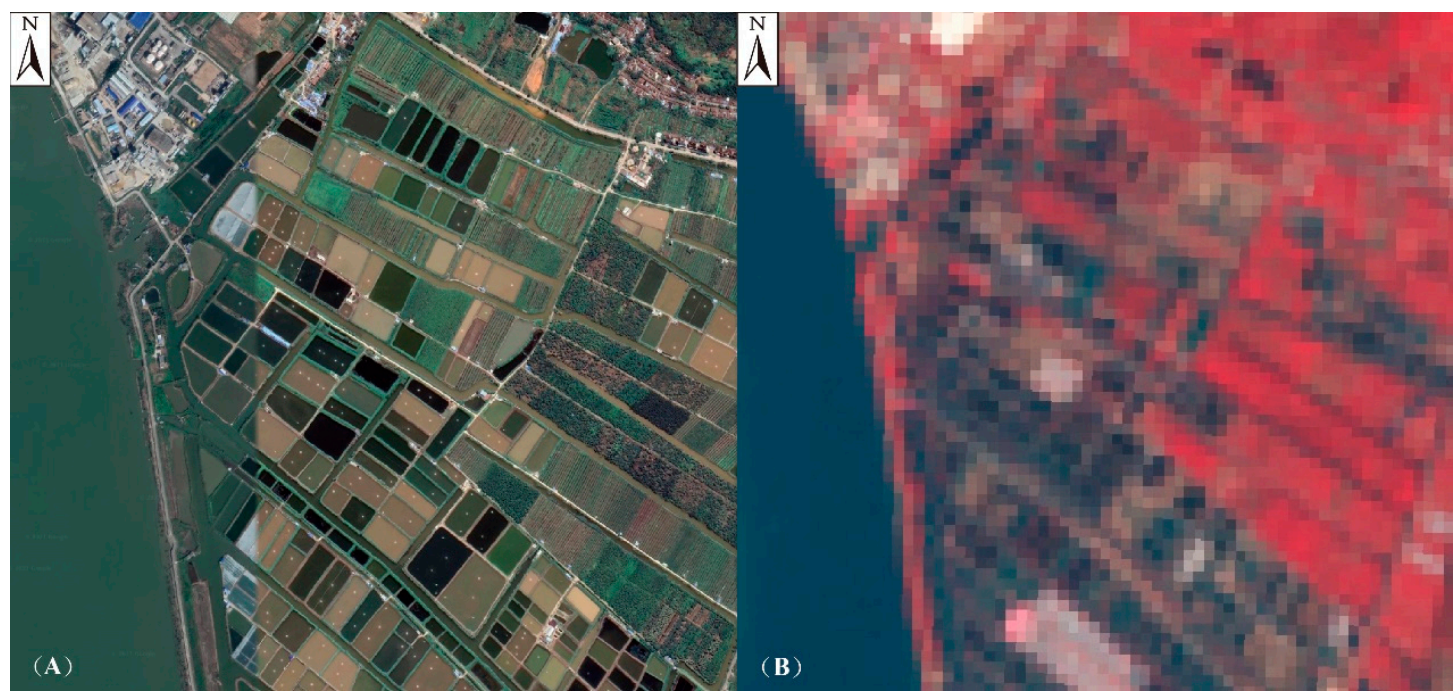

Figure 14. Fish ponds in Google Earth high resolution image (A) and Landsat image (B).

Table 2. Error Matrix of Classification Accuracy Assessment for Each Yearly Result.

\begin{tabular}{cccc}
\hline Year & Kappa Coefficient & Year & Kappa Coefficient \\
\hline 1986 & 0.81 & 2006 & 0.86 \\
1988 & 0.85 & 2009 & 0.83 \\
1991 & 0.84 & 2013 & 0.80 \\
1994 & 0.82 & 2015 & 0.81 \\
1999 & 0.80 & 2019 & 0.80 \\
\hline
\end{tabular}




\subsubsection{Comparisons with Previous Studies}

Previously, few studies were conducted on fish ponds in the entire Guangdong-Hong Kong-Macao Greater Bay Area. Many studies have been conducted in a specific city or a smaller area. Therefore, in the comparison, previous study results were compared with our results from the same specific areas. Previous studies about trends of dyke-ponds between 1978 and 2016 in Shunde, a district of Foshan City located in central GBA, reported that the spatial distribution of fish ponds in Shunde did not greatly change during 1988 and 1993 [24]. It was concluded from the comparison of fish pond distribution between these two years. Completing the gap of the time series by adding the fish ponds distribution in 1991 (Figure 15), we found that during this period, fish ponds in the eastern Shunde experienced a dramatic decrease, lost a large number of ponds, most of which disappeared in 1991.

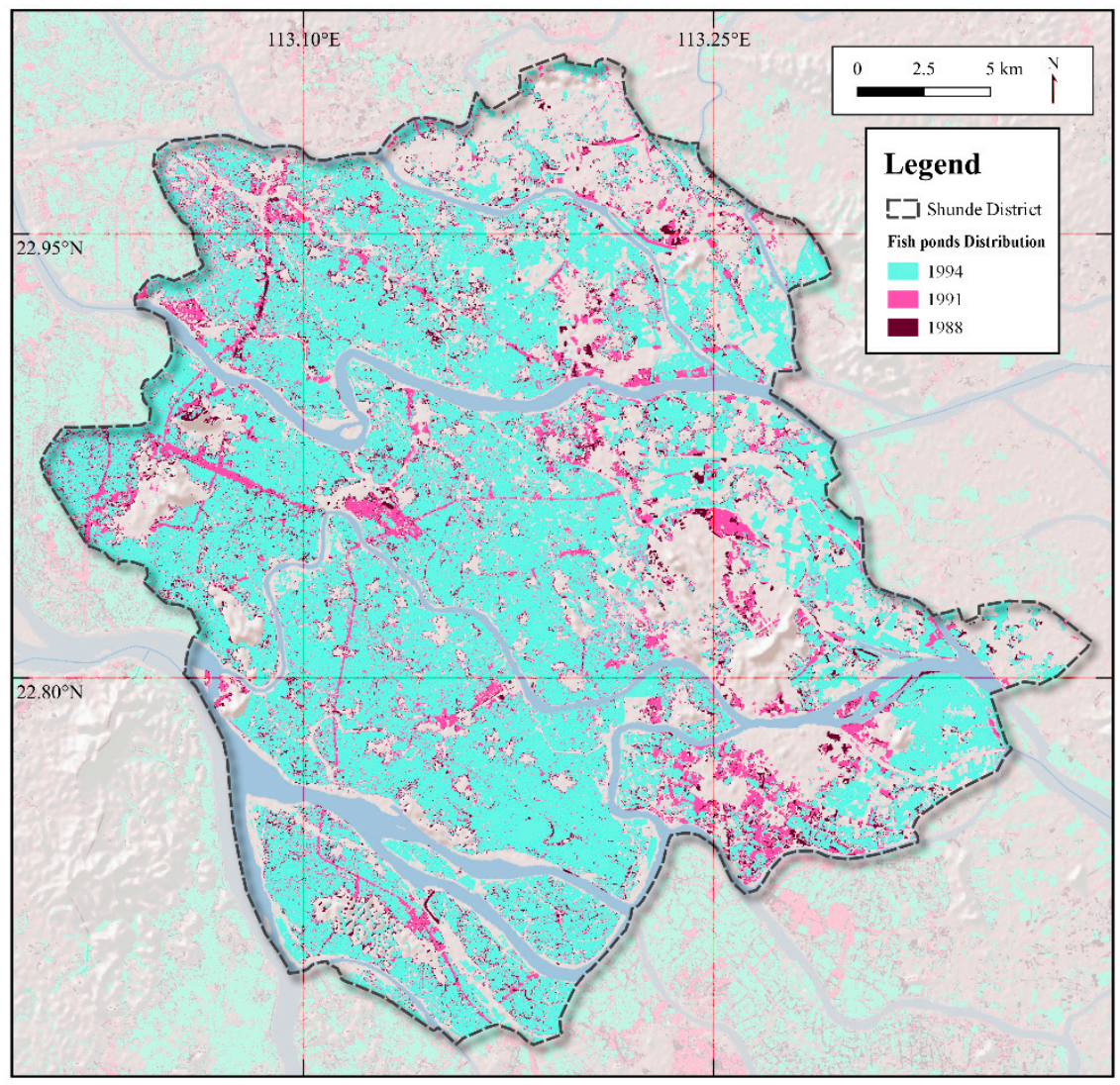

Figure 15. Spatial changes in fish ponds in Shunde District between 1988 and 1994.

Another previous study by Li [11] displayed the distribution changes of fish ponds in 1964, 1976, 1988, 2000, 2012 in Pearl River Delta region. The results indicated that fish ponds kept increasing in its area from 1964 to 2012 [11]. This study also covered the period of 1988 to 2012. However, due to some cities' boundaries adopted by the two studies are slightly different, resulting in false comparisons for such cities. The boundary of Guangzhou that two studies adopted are relatively consistent. Li's study displayed that the classification results of $1988,2000,2012$, were $41.17 \mathrm{~km}^{2}, 203.06 \mathrm{~km}^{2}$ and $213.44 \mathrm{~km}^{2}$, respectively. Comparing with this study's results in 1988, and 1999 and 2013 (no results available for the years of 1999 and 2012), which are $45.86 \mathrm{~km}^{2}, 190.56 \mathrm{~km}^{2}$ and $228.62 \mathrm{~km}^{2}$, respectively, the two results are basically consistent, with an averaged relative difference of $10.93 \%$. However, it should also be known that this difference may also be caused by the real difference in the latter two periods (1999 vs. 2000, 2012 vs. 2013). Despite the difference, the time series in our study more thoroughly demonstrate the trend of fish pond 
changes in the study area between 1988 and 2013 (Table 3). In addition, the obtained trends are quite consistent, but Li's study used merely 3-year data over a 24-year period, resulting in a harder response in sensitivity. This study revealed that fish ponds in Guangzhou actually experienced a fluctuation instead of a smooth increase, especially in the period of 1994 to 2013. Besides, the expansion of fish ponds happened before 2012.

Table 3. Comparison of the pond changes between Li's study and this study in Guangzhou for the period 1988 to 2013.

\begin{tabular}{ccccc}
\hline Year & Li's Study $\left(\mathbf{k m}^{\mathbf{2}}\right)$ & Year & This Study $\mathbf{( \mathbf { k m } ^ { 2 } )}$ & Percentage of Difference \\
\hline 1988 & 41.17 & - & 45.86 & $4.69 \%$ \\
- & - & 1991 & 117.62 & - \\
- & - & 1994 & 165.15 & - \\
2000 & 203.06 & 1999 & 190.56 & $12.49 \%$ \\
- & - & 2006 & 184.20 & - \\
- & - & 2009 & 185.51 & - \\
2012 & 213.44 & 2013 & 228.62 & $15.18 \%$ \\
\hline
\end{tabular}

\subsection{Possible Causes for Pond Changes in Different Cities and Future Speculation}

\subsubsection{The Growing Cities}

Guangzhou, Huizhou, Zhuhai, Zhongshan, Zhaoqing, Jiangmen-six cities in total were classified as growing cities. The reason was that compared with 1986, all of these cities experienced an increase in pond area in 2019. The peaks also appeared before 2019, showing a fluctuating growing trend.

Guangzhou's population increased by 1.67 million between 1990 and 2006, about 28\% in total, yet the actual product consumption was about 3.7 times of the previous amount. The aquatic products in 2006 was 4.9 times of that in 1990 [22]. The inflow of population and the expanded market stimulated the demands and development of aquaculture, resultant increase in fish ponds in Guangzhou before the beginning of the new century, especially in the Nansha District of Guangzhou. Therefore, Nansha District experienced a strong expansion from 1986 to 2013. After 2013, Nansha District was designated as a free trade zone, and Nansha Port was also developed as a manufacturing and industrial export, resulting in further changes in land uses and shrinking in fish ponds [25]. Huizhou was similar too. The area of fish ponds near the seaside also maintained a positive growth before the development of the petrochemical industry before 2006, and then gradually shrank with industrial development [26].

Zhaoqing City also achieved rapid growth in fish ponds from 1986 to 2006 through the reconstruction of low-lying sandy wasteland [27]. Subsequently, from 2006 to 2009 and 2013 to 2019, due to the impact of natural disasters, bacterial diseases, and dramatic price fluctuation in aquatic products, the risk of aquacultural development increased, which dampened the enthusiasm of farmers for aquacultural development, and the area of fish ponds showed a rapid downward trend.

Driven by the adjustment of the regional agricultural policy, the area of fish ponds in Zhuhai had increased significantly before 2006. During the period 1990-2006, local cultivated land experienced an accelerated loss, during which the net transfer area of cultivated land to the fish ponds reached $16,054.23 \mathrm{hm}^{2}$ [28,29]. Subsequently, urbanization developed during 2006-2009. As there were less cultivated land and forest land available for urbanization, the occupation of fish ponds was accelerated to a certain extent. The Government planned to accelerate the development of ecological fisheries and the construction of agricultural and fishery infrastructure to provide a guarantee for the development of fish ponds. Similarly, the Local Government of Jiangmen released a new policy [30] in 2009 to prompt aquacultural development the growth of the fish ponds in Jiangmen from 2009 to 2013.

However, from 2013 to 2019, Zhuhai has invested heavily in the development of ecological agriculture such as flowers, fruits and vegetables, and organic rice. The Government 
introduced modern agricultural industrial parks, such as the Yongcheng Horticulture and Taiwan Orchid Greenhouse Planting Base, and eliminated fish ponds with low economic and environmental benefits, causing the shrinking of fish ponds.

\subsubsection{The Shrinking Cities}

The fish ponds in Foshan and Dongguan showed an initial increasing trend followed by a significant shrinking. From 1986 to 1994, the area of fish ponds in Foshan City has increased significantly. Taking the Nanhai County in Foshan City as an example, the county became a pilot for land policy reform in 1987. Stimulated by the flexible land policy, the productivity has greatly increased. The traditional agriculture was drastically reduced and transformed into vegetable planting and aquaculture. After 1994, Nanhai county was cancelled and became a district of Foshan. In order to promote industrialization, the Government reduced the rent of collective land in rural areas to attract a large number of enterprises to settle in. The upgradation in the industry prompted a rapid expansion of built-up land, with an average annual growth rate of over 7\% [31]. In addition, township and village enterprises had sprung up all over Foshan. In 1991, the total income of township and village enterprises in Foshan reached 21.04 billion Chinese yuan, which increased by 3.84 times in 1997 [32]. The expansion of built-up land encroached on a large amount of fish ponds, resulting in shrinkage of fish ponds and its fragmented distribution. However, in the most recent 5 years, a series of development policies, such as the "Conservation and Development Plan for the Agricultural System of Fish Ponds in the Pearl River Delta, Foshan, Guangdong" and "Strategic Plan for the Implementation of Rural Revitalization in Guangdong Province (2018-2022)" [33] have slowed down the shrinking. At the same time, the Foshan Local Government has declared the fish ponds as an important agricultural cultural heritage in China, and combined it with the tertiary industry, which had a certain effect on protecting the fish ponds and increasing their outputs. Such measures have slowed down the shrinking trend from 2013 to 2019, but remained insufficient in reversing the shrinking trend.

\subsubsection{The Fast Shrinking Cities}

The number of fish ponds in Hong Kong SAR and Shenzhen was relatively small, but they have shrunk at a rapid rate (Figure 16). The fish ponds in Hong Kong are mainly located on the river alluvial plains in the estuary of the Shan Pui River in Yuen Long and Nan Sang Wai. In the 1980s, the development of fish ponds in Hong Kong reached its peak. However, with the rapid development of Yuen Long after the 1990s, the land used for the fish ponds in Nan Sang Wai had changed. For example, the original fish ponds were excavated and converted to a new channel of the Kam Tin River or recreated as smaller triangular ponds near the river channel. Moreover, the discharge of wastes in the process of urbanization had led to the continuous deterioration of the water quality of Shan Pui River, which is not suitable for aquaculture now, resulting in the disposal of local fish ponds.

The fish ponds in Shenzhen are mainly concentrated in the original Bao'an County. After the establishment of the Shenzhen Special Economic Zone in 1980, superior policies and other geographical conditions promoted the rapid development of industry. The demand for built-up surged, and changes in land uses led to a sharp decline in fish ponds over the past 40 years. Therefore, the urbanization is the major cause for fish pond shrinking in Shenzhen and Hong Kong. Besides, large amounts of aquatic products imported from mainland China was also an important cause for the shrinking of fish ponds in Hong Kong. 

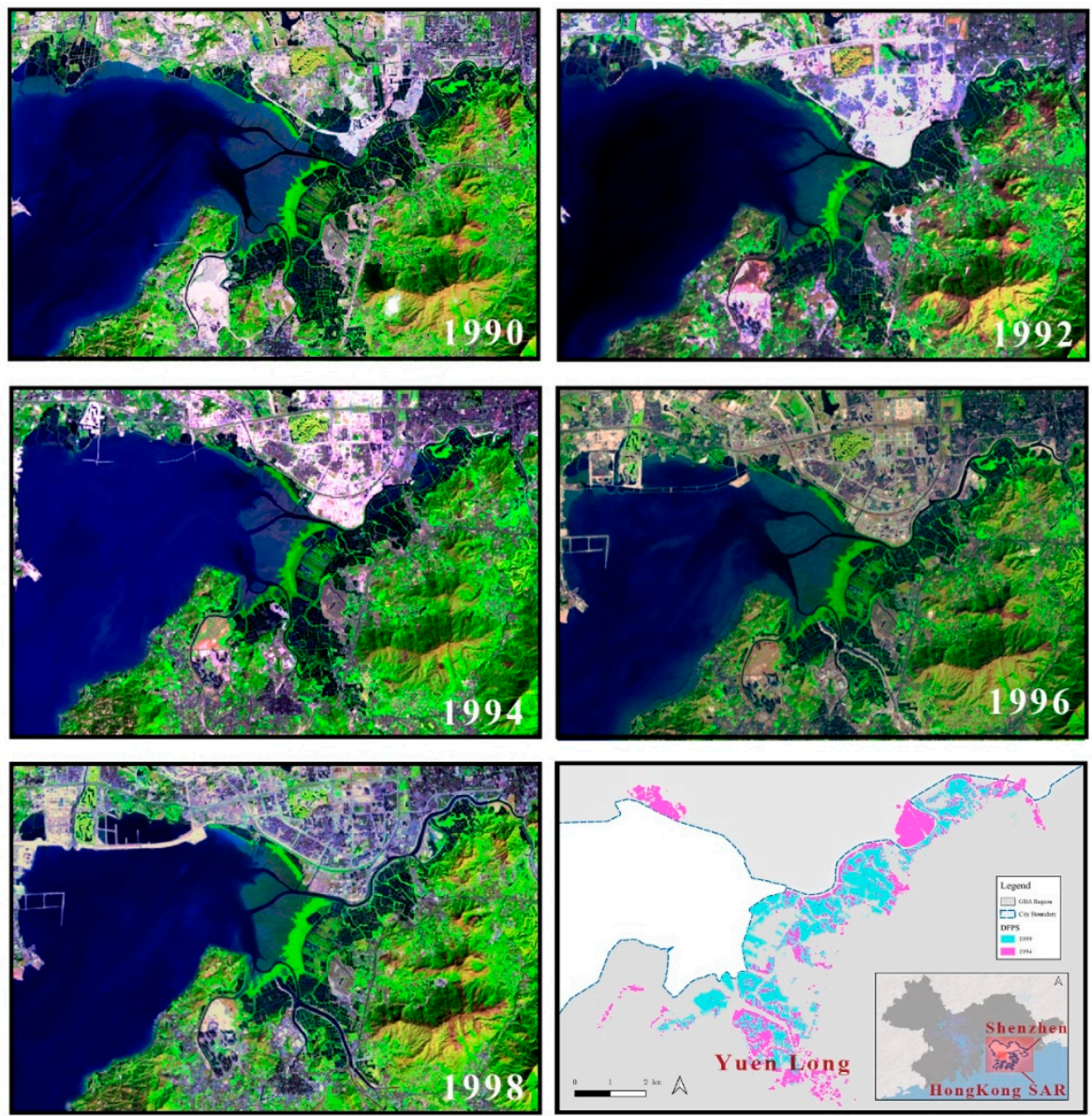

Figure 16. The rapid shrinkage of fish ponds in Shenzhen and Hong Kong SAR in the 1990s.

\subsubsection{Future Trends of Fish Ponds in GBA}

In view of the current trends of changes in various cities and the overall planning background of the Greater Bay Area, the shrinkage of fish ponds in the future will remain for a long time. However, the rate of shrinkage in various regions will vary greatly due to various drivers such as local development policies. It is expected that the development of fish ponds will tend to integrate with the tourism and service industry. The economic benefits of fish ponds will increase accordingly via excavation of the cultural value of fish ponds and construction of traditional aquacultural demonstration areas. Due to the differences in regional development and local government investment, the better evolution in fish ponds could appear in such regions where the economic development is quite high.

\section{Conclusions}

In this study, we analyzed spatiotemporal changes in mulberry-dyke-fish ponds in the GBA using Landsat satellite images obtained from 1986 to 2019. combined the measurements of standard deviation, coefficient of variation, Theil coefficient, water body change index as well as expansion coefficient, the spatiotemporal changes were quantified.

From 1986 to 2019, the fish ponds in the GBA showed an overall increasing trend in the first stage and a sharp decreasing trend at the second stage. The year of 2013 was a milestone. A total 25 study units in the two periods before and after 2013 were studied. It was found that 18 units were transformed into shrinking trend. Additionally, the causes for the fish pond changes were analyzed, and the future development of fish ponds was also predicted. The results proved that human activities have continuously influenced the spatial distribution and size of fish ponds in the past 40 years. The fish ponds had 
transformed from a near-natural ponds with different sizes and a near-natural random distribution in the early stage into an artificial distribution and an artificial shape.

The increased social demands were the major causes for the steady growth in fish ponds in the GBA from 1986 to the beginning of the 21st century. The market price of aquatic products directly affected farmers' willingness to develop and maintain fish ponds. The policies reflected the local governments' attitudes toward the development of fish ponds. Urbanization was the main cause of shrinkage in fish ponds. The shrinkage of Shenzhen and Hong Kong before 2013 was due to the encroachment of urban expansion, while Foshan was due to the introduction of a large number of enterprises to promote industrial upgradation. After 2013, the policy for the development of metropolis in the GBA was given priority, and the development tended to be economic development and industrial upgradation. the outputs of aquacultural ponds are relatively low, thus, the shrinking of fish ponds will remain in future. However, increasing the economic outputs of fish ponds through deep excavation of the cultural value and construction of some new aquacultural demonstration areas can slow down the shrinking trend and enhance the social and cultural values of fish ponds.

Author Contributions: Investigation, Z.C., X.Y., W.Z. and J.Q. data preparation, Z.C. and W.Z. writing—original draft preparation, W.Z. and J.Q. writing—review and editing, X.Y., E.P., L.R. and X.X. supervision, X.Y. project administration, X.Y., L.R. and X.X. Funding acquisition, X.Y. and X.X. All authors have read and agreed to the published version of the manuscript.

Funding: The National Natural Science Foundation of China (Grant No.: 41871017 and 41476152) funded this research.

Institutional Review Board Statement: Not applicable.

Informed Consent Statement: Not applicable.

Data Availability Statement: Not applicable.

Acknowledgments: The authors thank the anonymous reviewers for their careful reading of the manuscript and their many insightful comments and suggestions.

Conflicts of Interest: The authors declare no conflict of interest.

\section{References}

1. Liu, S.; Min, Q.; Jiao, W.; Liu, C.; Yin, J. Integrated emergy and economic evaluation of Huzhou mulberry-dyke and fish-pond systems. Sustainability 2018, 10, 3860. [CrossRef]

2. Zhong, G. The characteristics of dike-pond system and the practical significance. Sci. Geogr. Sin. 1988, 8, 12-17, 99.

3. Astudillo, M.F.; Thalwitz, G.; Vollrath, F. Modern analysis of an ancient integrated farming arrangement: Life cycle assessment of a mulberry dyke and pond system. Int. J. Life Cycle Assess. 2015, 20, 1387-1398. [CrossRef]

4. Nie, C.; Li, H. The integrated Dike-pond systems: Its new developments and ecological problems. J. Foshan Univ. 2001, 19, 49-53.

5. Chen, W.; He, B.; Nover, D.; Lu, H.; Liu, J.; Sun, W.; Chen, W. Farm ponds in southern China: Challenges and solutions for conserving a neglected wetland ecosystem. Sci. Total Environ. 2019, 659, 1322-1334. [CrossRef]

6. Li, M.; Zhang, Y.; Xu, M.; He, L.; Liu, L.; Tang, Q. China Eco-Wisdom: A Review of Sustainability of Agricultural Heritage Systems on Aquatic-Ecological Conservation. Sustainability 2020, 12, 60. [CrossRef]

7. Guo, S. The Value, Protection and Utilization of Mulberry Ponds in the Pearl River Delta from the Perspective of Agricultural Cultural Heritage. Trop. Geogr. 2010, 30, 114-120.

8. Liu, K.; Xie, L.; Zhuang, J. Analysis on the evolution of the spatial pattern of the dyke-pond system in Foshan city. Trop. Geogr. 2008, 28, 513-517.

9. Liu, Z.; Cui, W. Multi-temporal Remote Sensing Analysis of Foshan Dyke-Pond System. Guangdong Agric. Sci. 2017, 44, 126-130, 183.

10. Lin, M.; Ji, S. Analysis on mode change and landscape pattern of the Dike-pond agriculture in Zhongshan. Guangdong Agric. Sci. 2014, 41, 192-197, 205, 245.

11. Li, Y.; Liu, K.; Liu, Y.; Zhu, Y. The Dynamic of Dike-Pond System in the Pearl River Delta during 1964-2012. In Global Changes and Natural Disaster Management: Geo-Information Technologies; Springer: Berlin/Heidelberg, Germany, 2017; pp. 47-59.

12. Mao, Y. The Theoretical Basis and System Innovation of the Construction of Guangdong-Hong Kong-Macao Greater Bay Area. J. Sun-Yatsen Univ. 2019, 59, 173-182.

13. Han, X.L.; Yu, K.J.; Li, D.H.; Wang, S.S. Building the Landscape Security Pattern of Dike-Pond System with Urban Functions A Case of Magang Part of Shunde District, Foshan City. Areal Res. Dev. 2008, 123, 109-112, 130. 
14. Yan, Y.; Li, Y. The Comparative Study of Remote Sensing Image Supervised Classification Methods Based on ENVI. Beijing Surv. Mapp. 2011, 11, 14-16.

15. Gong, Z. Ponderation over the Flood Control Functions of the Artifical Landforms in PRD. Trop. Geogr. 2012, 32, 50-56.

16. Wei, C.T.; Hannes, B.T. Measuring urban agglomeration using a city-scale dasymetric population map: A study in the Pearl River Delta, China. Habitat Int. 2017, 59, 32-43. [CrossRef]

17. Yang, X.; Lu, X. Drastic change in China's lakes and reservoirs over the past decades. Sci. Rep. 2014, 4, 1-10. [CrossRef] [PubMed]

18. Hui, L. Regional inequality measurement: Methods and evaluations. Geogr. Res. 2006, 45, 152-160.

19. Ye, C. Change characteristics and spatial types of dike-pond in the Pearl River Delta. J. East. China Inst. Technol. 2013, 12, 315-322.

20. Zhang, W.; Xue, D. Urbanization base of city-land use expansion in the Zhujiang River Delta. J. Nat. Resour. 2003, 18, 64-71.

21. Cohen, J. A coefficient of agreement for nominal scales. Educ. Psychol. Meas. 1960, 20, 37-46. [CrossRef]

22. $\mathrm{Wu}, \mathrm{Y}$. Analysis of the indicators between urban metabolism and land use change in Guangzhou. Geogr. Res. 2011, 14, 478.

23. Yang, X.; Lu, X. Delineation of lakes and reservoirs in large river basins: An example of the Yangtze River Basin, China. Geomorphology 2013, 190, 92-102. [CrossRef]

24. Li, F.; Liu, K.; Tang, H.; Liu, L.; Liu, H. Analyzing Trends of Dike-Ponds between 1978 and 2016 Using Multi-Source Remote Sensing Images in Shunde District of South China. Sustainability 2018, 10, 3504. [CrossRef]

25. Li, J.; Du, Y.; Cai, A. Change Characteristics of Coastal Wetlands in the Pearl River Delta under Rapid Urbanization. Wetl. Sci. 2019, 17, 267.

26. Chen, J. The Evolution of Reclamation Area and Its Impact on Land Resource Utilization; Guangzhou University: Guangzhou, China, 2018.

27. Yang, M.; Qu, L.; Zhang, Y. The Driving Mechanism of Cultivated Land Change in the Development and Utilization of Core Regions in the Outer Peripheral of the Pearl River Delta in the Past Ten Years-A Case Study of Dinghu District. In Proceedings of the Annual Conference of China Land Society 2008, Hefei, China, 12 October 2008; pp. 599-603.

28. Wu, D.; Dong, Y.; Liu, H.; Ni, S. Analysis on the Spatial-temporal Changes of Cultivated Land and Their Driving Forces in Zhuhai. Trop. Geogr. 2009, 29, 472-476, 482.

29. Zhong, S. Reasearch on Coordinated Development of Regional Resources, Environment and Economy-A Case Study of Zhuhai City; Jilin University: Changchun, China, 2013.

30. Zhuhai Municipal Bureau of Agriculture. Work Plan for the Construction of Jiangmen Modern Agriculture Comprehensive Demonstration Base. 2009.

31. Liu, Y.; Lin, H. Spatial-Temporal Changes and Mechanism of Land Use in the Pearl River Delta from the Perspective of Property Rights Alteration: A Case Study of Nanhai District in Foshan City. Trop. Geogr. 2019, 39, 54-65.

32. Gui, D. A Preliminary Study on the Development Track of Foshan's Private Economy. Guangdong Econ. 2010, 162, 47-53.

33. Government of Guangdong Province. Strategic Plan for the Implementation of Rural Revitalization in Guangdong Province (2018-2022). 2019. 